$\xi=-1$

\title{
Building Information Modelling and Its Application in Digital Architecture to Achieve Sustainability
}

\author{
Seyed Asghar Hosseini
}

Master of Architecture, Islamic Azad University of Mahallat branch, Mahallat, Iran

\begin{abstract}
Using building information modeling (BIM ) method in architecture can reduce costs and time of project and satisfaction of beneficiaries is provided. By the process in BIM, we can create three-dimensional modeling of building volumes and by the aid of all beneficiaries and executive authorities in project life cycle, we can achieve the best result. The integration and benefits sharing in this method caused that the best quality is considered at proper time and cost. Creating a systematic view in design of a building in which all internal and external beneficiaries can use project executing is a good goal. This study introduced BIM and its application in design and the impact of its use on achieving digital and sustainable architecture of buildings. The introduction of various components of this method with analytical and descriptive approach by evaluation of students all around the world can have a good view of this technique. The increase of perception of authorities of this industry of new technologies of digital design and BIM can improve the culture of construction works in the country and increase economic power. In case of using BIM from the beginning of designing a building and integrating it with digital architecture, we can expect better performance of buildings.
\end{abstract}

Keywords: Building Information modeling, New construction technologies, Digital architecture, Sustainable development

\section{Introduction}

Great problems in construction industry created various technologies. Low budgets, limited skillful force, intense plans and continuous request for delay caused many problems in construction. These items led into many mistakes re-work. Many people in construction industry mostly think of some solutions to reduce these challenges. In the past, these relations were traditional. This is shown in Image 1 and it requires the change of views of people.
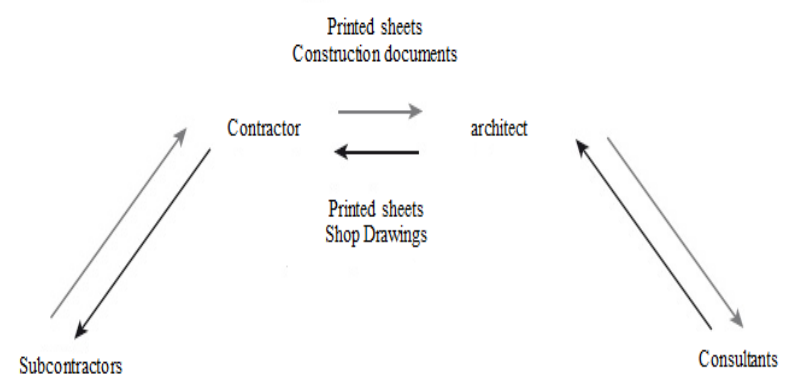

Image 1- Traditional method of design review [1]

The concept of BIM was presented for the first time by Professor Eastman in 1970. The solution was BIM. Then, some changes were made in the model and the existing terms were explained by Autodesk Company. This means the significance of BIM in computer-aided designs. Various companies presented different definitions of BIM and they built different software. The main branch of this system is continuous and immediate access to qualitative information of design, scheduling and cost of project execution. Table 1 shows some of the software with their application in construction industry [2].
Table 1- The wide range of various software of BIM with various applications (2)

\begin{tabular}{|c|c|c|}
\hline Application in BIM & Company & Software \\
\hline $\begin{array}{l}\text { Planning, finding work } \\
\text { interference, meter and } \\
\text { estimation }\end{array}$ & Autodesk & $\begin{array}{l}\text { Navisworks Man- } \\
\text { age }\end{array}$ \\
\hline $\begin{array}{l}\text { Planning and finding } \\
\text { interferences }\end{array}$ & Bentley & ProjectWise \\
\hline $\begin{array}{ll}\text { Coordinating } & \text { various } \\
\text { sectors models } & \end{array}$ & Gehry Technologies & $\begin{array}{l}\text { Digital } \\
\text { Designer }\end{array}$ \\
\hline Planning & Innovaya & Visual Simulation \\
\hline $\begin{array}{l}\text { Physical coordinating the } \\
\text { applied components }\end{array}$ & Solibri & $\begin{array}{l}\text { Solibri } \\
\text { Checker }\end{array}$ \\
\hline Planning and work design & Synchro Ltd. & Synchro \\
\hline $\begin{array}{l}\text { Structure modeling, shop } \\
\text { drawings, using time } \\
\text { planning information }\end{array}$ & Tekla & Tekla Structure \\
\hline $\begin{array}{l}\text { Coordination, planning } \\
\text { and estimation }\end{array}$ & Vico Software & Vico Office \\
\hline
\end{tabular}

Various progress as using 3-D modeling are used to present architectural structures in construction industry. These images can help the architects, engineers to transfer real concepts to client and they are important tools for sale, investment on construction industry. However, all the capabilities of these technologies are not used.

The main aim of BIM is creating common database to be used regularly by all design, construction, owner and user groups (key project beneficiaries). This modeling is used as integrated and in case of adding time aspect to create scheduling structure, it is identified as four-dimensional modeling. In this case, materials and workshop drawings are provided automatically for various sectors of building. In the past, there was a one-way relationship between components and key beneficiaries. Today, by new tech- 
nologies and project management knowledge in this section, the relations are in details. This is shown in image 2 [3].
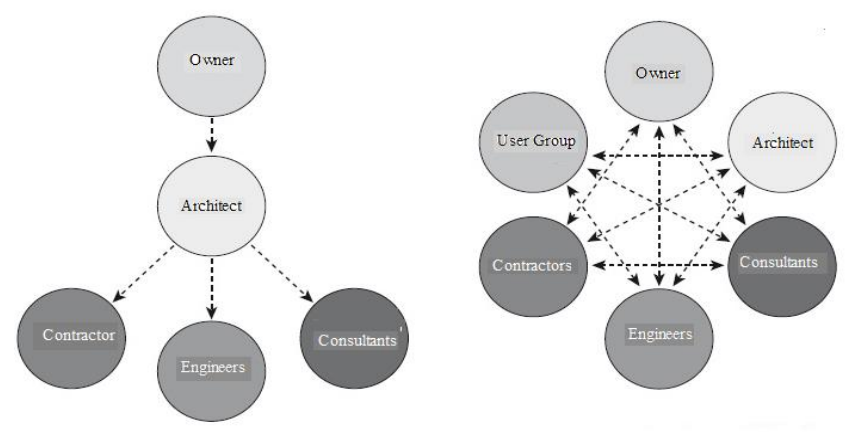

Image 2: The conventional structural model compared to new structural model in construction collaboration [2]

The important advantage of this method is using all views of designer in the work. Thus, graphic documents are important in project development and unnecessary data are omitted. Construction cost saving is estimated by BIM ranging $15 \%$ to $40 \%$. The costs reduction is with increase of final product quality and can be useful by giving guidance to use good methods of maintenance for users and authorities presenting loans.

Development of supervision of designers in building is an important advantage of using BIM.

Each of these decisions is taken in various sectors of project and other sectors are not used. Thus, it leads to non-integration among various sectors in construction project. Also, this inconsistency leads to non-coordination, instability, energy waste, cost waste, increasing operation time and lower project return. Thus, if we use an organized structure like BIM to eliminate these problems, in addition to increasing efficiency among various elements of project, we can be hopeful regarding the increasing productivity. Digital architecture is one of the latest construction information. This study after introduction of BIM, we investigate the impact of using this system on achieving digital construction architecture and sustainability. At first, some of initial concepts regarding new modeling system and digital architecture are introduced separately and some items are smartization of construction design by BIM system can be evaluated [4]

\section{Method}

This study is an analytical-descriptive design and evaluates the structures and qualitative factors of BIM. Using internet and library references and expert information and relevant fields in architecture technology, project management and construction and considering sustainability principles in architectural designs draw a road map to achieve future goals in construction industry. This method can reduce the costs considerably and can have crucial role in achieving satisfaction of key beneficiaries. After performing various evaluations in all over the world and comparison of design by CAD with BIM, we explain practical applications of this method in construction. Finally, the various advantages of this method and quantitative and qualitative approaches are considered to achieve sustainable architecture goals

\subsection{Building Information Modeling (BIM)}

According to the definition of national commitment of BIM in US, BIM is defined as: Presentation and digital display of performance and physical features of a building. BIM model is the common information source with information data of building as a reliable basis to take decisions in project life cycle. The information is used from ideation in design to building destruction. The basis of this method is various beneficiaries collaboration in various stages of project life to enter new information and extract the required information or make changes in the information .

BIM indicates the computer model to simulate plan, design, execution and performance of building. The required model is a digital presentation of building and based on the need of user, we can extract proper information. We can achieve the information to take decisions in construction and delivery of building [5].

BIM is not only using software, it is application of software and relevant trend. This made some changes in work flow and delivery of construction projects. BIM presents a new paradigm in construction industry leading to better consistency of people with different qualifications. This technology has the potential of improving productivity among key project beneficiaries [6].

Modeling, repair, renovation, reconstruction, supervision on the work of contractors, utility services of buildings, evaluation, design of construction projects are possible in the concept as "BIM" or building data modeling. This method indicates the solution of information simulation of building as developed in recent years in construction industry issues. Image 3 shows a sample of initial structure of BIM.

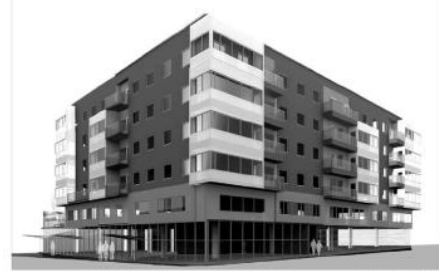

Image 3- A 3-D image to display BIM principles [1]

Three branches of architecture, engineering and construction (AEC) were gathered over time and created similar needs. This led into time and cost saving in civil projects and had important role in improvement of quality of construction industry. BIM is a term published by AEC recently and models the building as 3-D [7].

BIM system is a sample of the newest 3-D models for simulation of planning, design, construction and operation in civil projects (simply, it means that in this system instead of conventional drawing, a sample of a 3-D model as space, place and time are designed and are used in a civil project. and the aim is integration among various teams in all stages of work). This system helps us to build what should be built in a cyber space and in case of any problem in each stage of construction as design, implementation or operation, the problems are eliminated better. For example, we can refer to the light and good light severity in various parts of building. As we didn't start work execution sector, we can use simulation software to analyze in internal sections. This is shown clearly in Image 4. In each point, a value is used as severity of light in luxury unit. By this method, internal lighting is started without completion of building and we can achieve the required quality at the minimum time. 


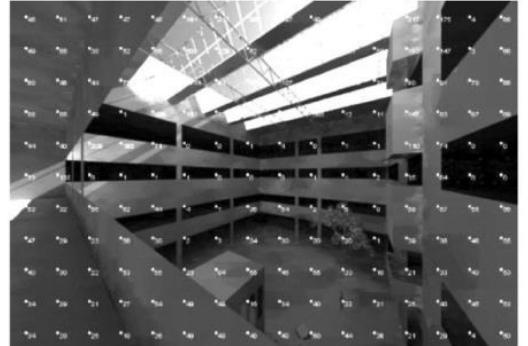

Image 4- A render of internal structure of building in which light severity is shown by value. Good light for various activities is estimated by this method [1].

Generally, BIM is introduced as it adds 3-D modeling with specific features to 2-D drawings. The specific feature for each of design member in BIM besides 3-D physical nature has an array of information of various activities of construction management. The information is regarding entire project life cycle from the beginning to the end [7].

\subsection{The position of design inside BIM}

BIM is beyond the computer-aided design and it is a modeling system based on database. in BIM system, design process starts with building a model. These components and their relations are identified carefully. This component stores the entire information of its features and by any change in its features can compare itself with the new design. These principles and comparison between the CAD and BIM are shown in Image 5.

BIM is a central core in building and other relevant factors as architects, engineers, structure, mechanical and electric systems, manufacturers and design executers and finally owners are used as marginal elements [8].

A BIM model besides establishing digital relation between various components of design can investigate various design scenarios as virtually for all beneficiaries. In this three, four Dimensional modeling system, building is considered as the main core acting independently and other elements of building (e.g. ceiling, windows, doors and stairways, etc.) are dependent elements around the central core.

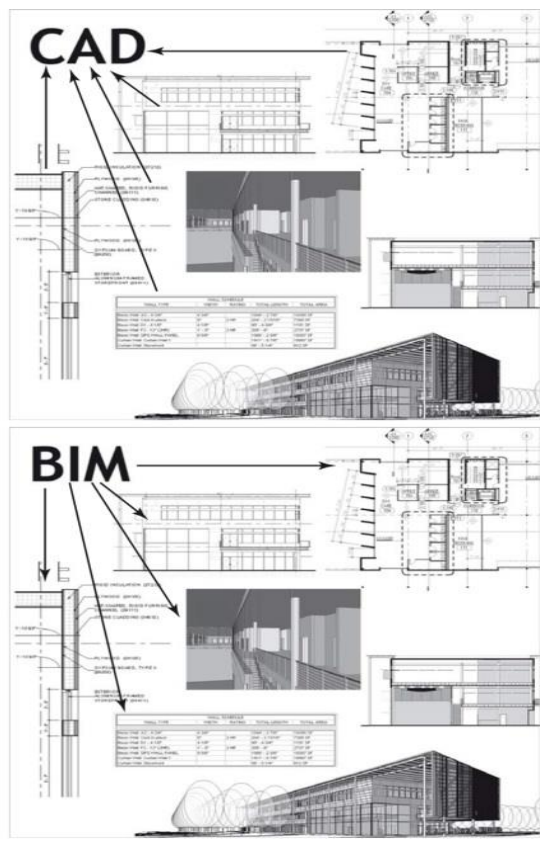

Image 5- The image comparison of CAD with BIM (1)
In other words, by this new technology, building is defined as an object that can be turned into a 3-dimensional object. Thus, BIM stores the entire information of building as a central core and enables to connect its dimensions. BIM system designs a construction project in a cyber space. By BIM technology, an exact cyber model of a digital building is made.

After the end of modeling, the computer modeling includes exact geometry and information of operation, construction and required activities to fulfill the building and an example of these modeling is shown in Image 6 [8].

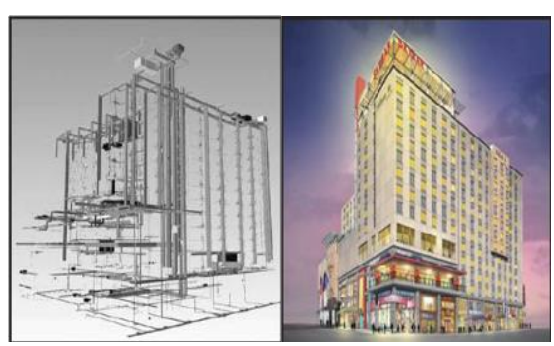

Piping model of houses B. Architecture model

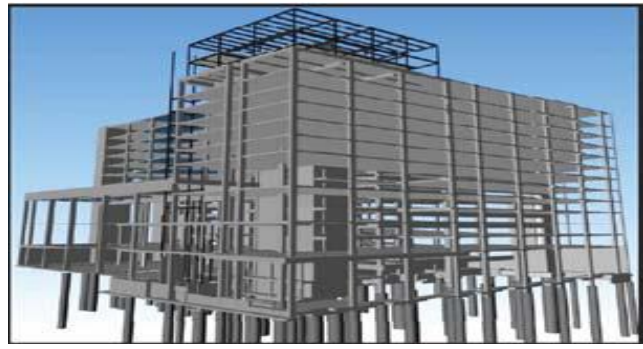

)Structural model d:Four-D model (3-d+ scheduling)

Image 6- Using BIM for project Hilton Aquarium (9).

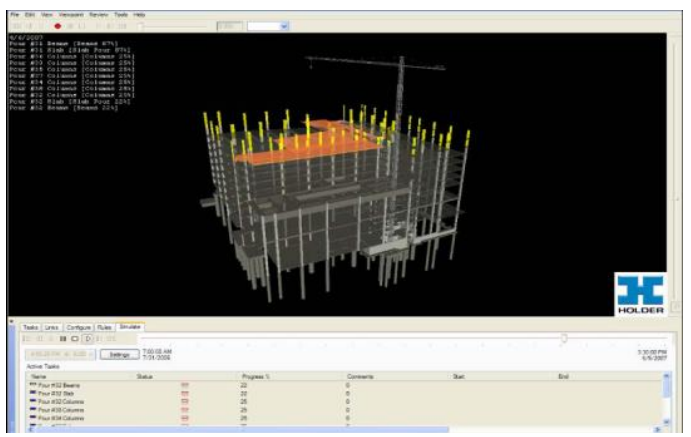

\section{IT capabilities in digital architecture}

One of the advantages of rapid IT growth is development of the systems measuring the surrounding changes and react to them. This ability in control of changes leads to the change in our surrounding physical environment namely the buildings we live or work in them. One of the changes is growth of intelligent buildings, the buildings combining the ICT systems and creating an easy integrated system with high security, useful from economic aspects and low cost. 


\section{Digital architecture}

In this method, the building by stimulating the sensors in the building can respond the information. In nomadic life style, architecture is a tangible movement. Their tents are mobile structures as gathering and the nomads can carry them. The mobile structures are considered as portable in movement architecture. Fox defines movement architecture as "a building with varied, mobile location and mobile geometry. He explained movement systems and one of them was slide system. Thus, the concept of mobile architecture is not an intelligent concept and it is a type of ability controlling the structures and moving its various components [10].

\section{Building with digital architecture}

The digital building indicates strong interaction of information among various sectors of building. The building sectors include all components important in managing the building. Some sectors as HVAC, mechanical sectors, construction, control of access, security, management, lighting, maintenance, local network and energy management. An intelligent building means the control of components of a building by the users applying computer to fulfill the needs. The needs include efficiency, usefulness, energy storage, fun, happiness, comfort, capital return and low life costs.

In international symposium of architecture in 1985 in Toronto: It was stated that a digital building is a set of innovations (technological or not) with a complete management and two features of capital return. This definition besides reminding the innovation and technology, it states that one of the goals of digital architecture is that the buildings are designed to increase capital return. Reductions of costs (output and usefulness) are the goals considered by controlling systems. A building by using modern technology can control various equipment automatically. This definition shows the information exchange among controlling components and controlled components in digital buildings [11].

\section{BIM in digital design}

The development, production of computer model is used to simulate planning, design, execution of BIM. The model of BIM is a digital model full of data, object-oriented, intelligent and parametric and each of its visual outputs and data are used to respond the various needs of users. Thus, the user can extract and process the required data from BIM model and achieves the information for decision making and improving the process of investigation of facilities.BIM model has the information of building including physical-performance features and project life cycle as a series of intelligent objects. For example, ventilation in BIM model is with the data regarding suction, performance, maintenance, air flow speed and its cleaning requirements. A BIM model defines the geometry of building, spatial relations, geographical information, value and features of building, costs estimation, list of required materials and project tables. This model can show the entire building life cycle and the values and features of materials can easily be extract from BIM and various parts can be separated easily. The systems can be shown in relation to the whole or group of building facilities. The construction documents as drawings, details, proposed processes and other features can be related easily.

\section{Optimization of digital design by BIM}

The follow up of design team to achieve adequate information for decisions is necessary. For example, a design with open approach can present the design with the maximum light and daylight. In the other words, the design in a BIM system considering various dimensions in design can consider even the sun reflection on a building. Thus, it shows maximum power of building in using light and sun energy. The various choices of design in BIM model can consider various states of visualization, time, cost quantity, quality of design and energy analysis in a building and these items can be available at any time. BIM by digital design and providing development by designers can make the required changes on the building design [9].

By a BIM model, various items of digital design can be analyzed and to achieve standard principles, it can be performed easily and in a modeled and digital designed building, we can documentize the information to achieve this issue even for long time. Simply, in design process, with common and old systems, good ideas can be presented for digital design but for various reasons, it can not be performed. Thus, by a BIM model, he can document all the god ideas and stores in a digital file to use them later (9).

\section{Using BIM in visualization of building with digital architecture for sustainable design}

One of the most important features as the fame factor of BIM to designers and civil engineers is visualization process. A BIM model enables the architects and engineers to turn the maps and 2$\mathrm{D}$ documents to digital advanced designs and observe the building in details. Thus, they can observe all materials of a building and its componets performance in each period, above all before turning the design to brick, mortar or metal and gypsum. With all these abilities, a BIM model can present a good set of common documents in building as reliable and presents them as documented at any time to the designer, architect, structure engineer, client and even user (9).

\section{Using daylight for sustainable design by BIM}

Using natural light for buildings lighting not only leads to comfort and high adaptability of residents with living place, electricity consumption is reduced and heath and energy of a building are reduced.

The sustainable and environment-friendly design with high efficiency has achievements regarding effective relation and combining solar energy in design. In common and old designs, using light was not effective or it was rarely. By introduction of new BIM system and computer software, the design by architects and designers considered these features as organized in buildings design [9].

The images 7, 8 show some examples of this design. 


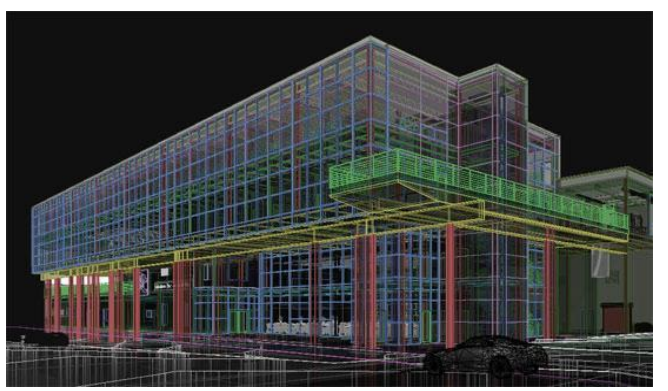

Image 7- An example of visualization of high-rising buildings by BIM

This process is used in common designs but due to high use cost, it is not costly.

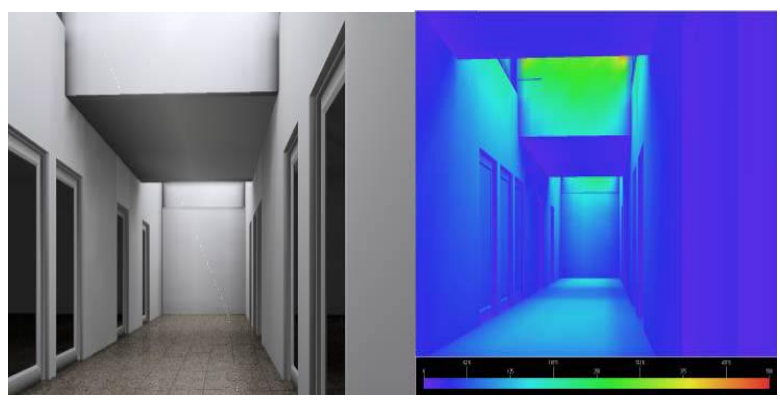

(a)

(b)

Image 8- Using daylight by BIM

\section{Energy sustainable development in dig- ital buildings by BIM}

The consumed energy analysis in design strategy of a building is vital to consider some strategies to reduce energy consumption. The energy analysis plans are available for a long time but due to the lack of exact facilities, the software is used rarely in design. Thus, most companies apply foreign resources as fissile fuels, etc. to provide energy (in terms of time and cost) and performance information of building energy can be available in project fixed points. Now, by BIM software, the design information is used better to complete analysis and these an analyses are done by regular times by designers [9]

The integration of various design choices as architecture, structure, mechanic, electric, etc. in a building is one of the features of this technology and it is done by engineering analytical systems. These inputs can consider various choices on design and considerable saving in costs can be resulted.

Various dimensions of digital design with BIM

Table 2 shows a list of some of modeling states in BIM and a summary of their use. Among them, VR is unfamiliar and this model presents a tool to experience real simulation in visual environment [8]. 4D modeling simulates time, place and planning of construction process but VDC is using BIM in design.

Table 2: The existing differences among various BIM approaches Ding, Zhou , Akinci, 2014.

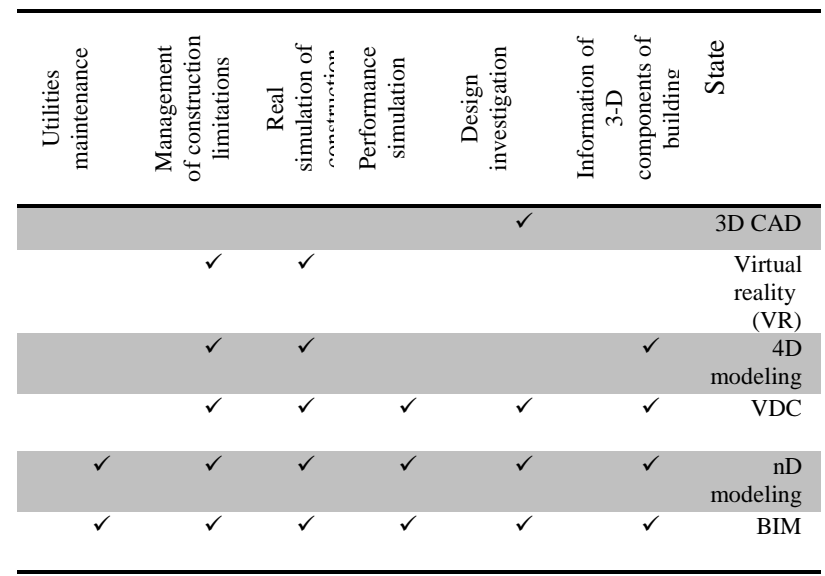

The framework of using BIM is based on three sections: Management project scope, beneficiaries and design and construction stages. In image 9, these three sections and their relations of the framework are shown. For example, a1a2a3a4 is using BIM use for safety management in terms of owner and b1b2b3b4 is using BIM in cost management in terms of other beneficiaries and in this case, owner, contractor and supervisor are agents of owner. $\mathrm{c} 1 \mathrm{c} 2 \mathrm{c} 3 \mathrm{c} 4, \mathrm{~d} 1 \mathrm{~d} 2 \mathrm{~d} 3 \mathrm{~d} 4$ are BIM application areas to evaluate design in planning, survey, design with other beneficiaries. This matrix structure can create proper perception of information and their location. In this framework, BIM application in building industry can have six various stages based on project management duties useful for beneficiaries (8).

Image 9- Framework of application of BIM (8)the best suited method for solving course timetabling problem and capable of efficiently providing the feasible timetable.

On the other side, the hard constraints and soft constraints are carried out to observe the Course Timetabling Problems in classification table. The survey shows the classification table of the hard and soft constraints provides different point of view based on some literature reviews. The details of the classification table are shown in Table 1 below. 


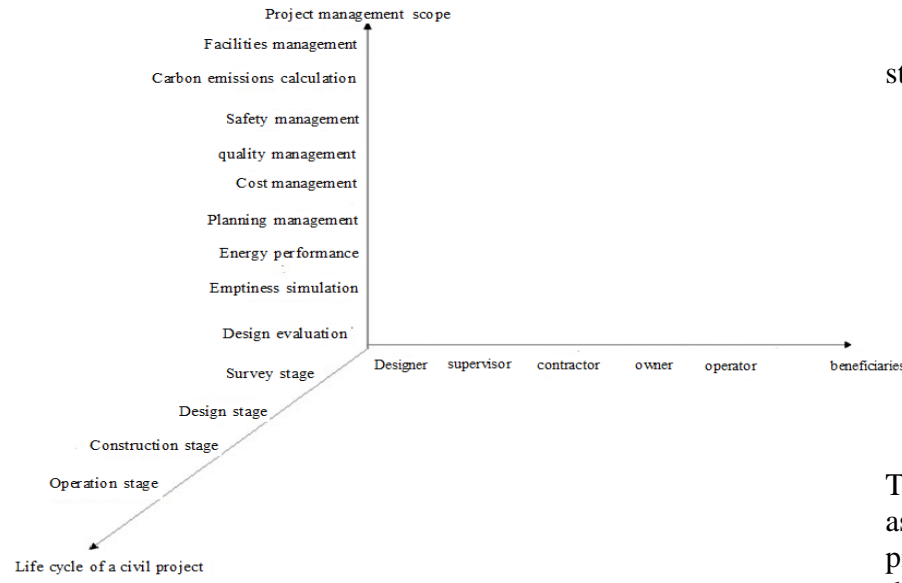

Image 9: Framework of application of BIM (8)

\section{Conclusions}

BIM has changed design, construction and using from buildings to achieve profit in justification of using this method by BIM. This method presents a new paradigm in construction industry as recommending the role of key beneficiaries in project. The combination of it can have better result and high return among the project creators. The specific concepts as pre-fabricated and modular of buildings in construct projects are other advantages of this method. Based on the speed of using BIM systems in various design processes, CAD convention systems can be replaced with BIM advanced systems and consultants can use great advantages of this method. The progress of various communication industries as smart phones with optimized capabilities of simulation designs can enable the owners and project managers to achieve high benefits in operation. There are great problems in BIM. The most important problems in our country are the lack of documentation of construction processes as limiting the knowledge for people. The review in consultant structures and style of works and documentation can lead to considerable changes in future. Due to intelligent nature of all members in BIM model and reduction of error in human resources, avoiding interference of various parts in execution, increasing safety of work and workers, the changes in project architecture and satisfaction of customer and all various hypotheses in project are other advantages of modeling with BIM system. The advantage defined in the project model based on the needs and presenting high quality products can cause that intelligent building is one of the important products. A BIM model is used for a wide range of goals as:

- $\quad$ Good drawings of construction and design

- $\quad$ Rapid and high quality design with sharing information and re-use in design

Control of construction costs and effective environmental conditions

Better design and good interactions with key beneficiaries to achieve good results with good quality at good time, better perception of client requirements and doing his requests at proper time

Elimination of costs of changing in project performance (or reducing them)

Review of standards

Facilities management

Management, estimation and costs reduction

Construction order
Determination of involvement, interference during construction

Visualization

Effective and rapid processes

Better and exact design

Better service to customer

Life cycle data

Objects and construction components basis

Saving in project execution time

Increasing safety in construction

Claim reduction

The goals achieved by building an intelligent building include all aspects of life. Productivity, high output, energy storage, fun, happiness, comfort, reducing life costs and increasing building life are the examples of these goals achieved by building intelligent buildings. The architecture and building space should have the features responding the needs of users, environment and sustainability. Digital architecture with BIM is restricted to one or two types of reactions and all actions are statistic, dynamic, internal and external are included. BIM and sustainable architecture design has not definite relation with each other but this relation is imagined and is fulfilled in future. Today, to achieve a better quality in design, we need effective knowledge management in construction processes. This perception can direct us to achieve a common point and various activities. By this solution, we can have healthy plant with high quality life. All future researches should help us to achieve these goals. For optimization of national researches, good quantitative and qualitative investigations in academic theses can be considered. This causes that we have good perception of this approach in the country. Based on arid climate and specific conditions of building activities in this climate, we need various evaluations and case studies for objective and optimized perception of efficiency of BIM in Iran. .

\section{References}

[1]. Eddy Krygiel, B. (2012). Green BIM: Successful Sustainable Design with Building Information Modeling. Chicago: Wiley.

[2]. Smith, D. (2007). An Introduction to Building Information Modeling (BIM. Journal of Building Information Modeling.

[3]. Lazovik, A. Kaldeli, E. Lazovik, E. Aiello, M. (2009). Planning in a Smart Home: visualization and simulation. 19th International Conference on Automated Planning and Scheduling, 13-16.

[4]. East.W. (2009). Performance Specifications for Building Information Exchange. Journal of Building Information Modeling.

[5]. AGC. (2006). The Contractors' Guide to Building Information Modeling. Arlington, VA: Associated General Contractors of America.

[6]. Hardin, B. (2009). BIM and Construction Management. Indianapolis: Wiley Publishing.

[7]. Kymmel, W. (2008). Building Information Modeling. McGraw Hill Inc.

[8]. Ding, L., Zhou, Y., Akinci, B. (2014). Building Information Modeling (BIM) application framework: The process of expanding from 3D to computable $\mathrm{nD}$. Automation in Construction

[9]. Energy, U. D. (2003). Energy Efficiency and Renewable Energy Network (EREN). Atlanta: Center of Excellence for Sustainable Development.

[10]. Leicht R. M., Messner J. I. (2007). Comparing traditional schematic design documentation to schematic Building Information Model",. Bringing ITCKnowledge to Work. Maribor: 2Proceedings of the 24th W78 Conference.

[11]. Wong, J.K.W., Li, H. (2005). Intelligent building. Automation in Construction 143-159. 